\title{
FEEDING TERRITORIES AND BREEDING SUCCESS OF SOUTH POLAR SKUAS
}

\author{
FRITZ TRILLMich
}

\begin{abstract}
Territorial and foraging behavior of the South Polar Skua (Catharacta maccormicki) were studied in 1971-72 at the Cape Hallett Adélie Penguin (Pygoscelis adeliae) rookery. The skua population was at maximum 98 pairs, and the Adélie Penguin population was some 43,000 pairs. The size of the skuas' territories varied between 0.5 and 1.8 ha (between 730 and 3,190 penguin pairs). Areas between adjacent territories overlapped. The behavior of three dyemarked pairs in their territories is described. A large enough feeding territory in the penguin rookery apparently enabled certain skua pairs to subsist exclusively on a penguin diet throughout the whole skua breeding season. Skuas breeding farther away from the penguin rookery usually defended only nest territories, which were much smaller than the above all-purpose territories. They hunted in the northwest part of the rookery in "preferred feeding areas" that were not defended against other skuas. Some pairs apparently foraged at sea. The number of skuas hunting per unit area is about sixfold in the parts of the rookery used by skuas as preferred feeding areas, but no resulting decline in penguin breeding success could be found. The breeding success of skua pairs with feeding territories was significantly higher than that of pairs with preferred feeding areas. The possible causes of this difference are discussed.-Max Planck-Institut für Verhaltensphysiologie, Ethologische Abteilung, 8131 Seewiesen, West Germany. Accepted 3 May 1976.
\end{abstract}

IN the Ross Sea area of the Antarctic the South Polar Skua (Catharacta maccormicki, subsequently termed skua) frequently breeds close to rookeries of the Adélie Penguin (Pygoscelis adeliae, subsequently termed penguin). Maher (1966) considered the skua-penguin association to reflect long-term predator-prey adjustment. He stated, "It is probable that the skua could not maintain itself in Antarctica if it were not for the Adélie." But Young (1963a, 1963b) thought this association was due to the scarcity of suitable breeding places for either species, resulting in the use of a common habitat. He showed that the skua acted mainly as a scavenger in the penguin rookery and pointed to the existence of skua colonies in McMurdo Sound, far away from penguin colonies, where the birds must live on seafood only.

The potential amount of food available to skuas within penguin rookeries varies considerably. At Hallett, where Maher (1966) pursued his study, there were at that time about 350 penguin pairs/skua pairs, whereas at Cape Royds there were only about 230 penguin pairs/skua pairs (Young 1963b), and at Cape Crozier about 150 penguin pairs/skua pairs (Wood 1971). Young (1963b) noted that at Cape Royds 6 out of 17 breeding skua pairs took part of their food from the 1,400-pair penguin rookery. These 6 skua pairs defended territories containing between 90 and 540 penguin pairs. D. and C. Müller-Schwarze (1973) at Cape Crozier, where 950-1,000 skua pairs and about 150,000 penguin pairs breed (Wood 1971), showed that skua pairs breeding near the edge of the penguin rookery defended adjacent parts of the peripheral rookery as territories and that skuas breeding farther inland, away from the rookery, apparently foraged all over its central parts and beaches. In both these penguin rookeries, the food available to the skuas seemed to be rather limited. That they utilize it fully is evident from the fact that no carcasses of penguin chicks are left lying around at the end of the breeding season. At Hallett many chick carcasses remain untouched after the penguin breeding season (Reid 1964), which supplement the skua diet in the following spring.

During my stay at Hallett Station in 1971-1972, I investigated how the potentially 
greater food resources at the Cape Hallett penguin rookery affected the territorial and foraging behavior of the skuas and how the association of the two species influenced their breeding success.

\section{TERMINOLOGY}

A rookery is a geographical area containing one or more colonies (groups) of breeding penguins and a landing beach used to reach the nesting grounds from the sea (after Penney 1968). A colony is a geographically continuous group of breeding penguins whose territorial boundaries are contiguous (after Penney 1968). "A territory is any defended area" (Noble 1939).

Three narrower terms need special definition: A feeding territory is a space that a skua pair exploits and defends against other skuas. A preferred feeding area is any part of a penguin rookery in which a skua hunts regularly without defending it against other skuas (no skua has been noted to have both a preferred feeding area and a feeding territory). A nest territory is the area immediately surrounding the nest itself; it contains no food for the skua, but it is vigorously defended against other skuas. The nest territory may be located within the feeding territory, adjacent to, or completely separated from it. Whenever the term "territory" is used in this paper, it signifies both feeding and nest territories together.

The breeding cycle of the penguins is described with Penney's (1968) terms. Perdeck's (1960) terms are used to describe the behavior of the skuas.

\section{METHODS}

From November 1971 to 22 January 1972, I studied the foraging behavior of marked skuas in the penguin rookery at Hallett Station $\left(72^{\circ} 19^{\prime} \mathrm{S}, 170^{\circ} 13^{\prime} \mathrm{E}\right)$, Antarctica. Many skuas had been banded with colored and aluminum bands by previous investigators and could be recognized individually.

A creek trap (after Becker in Bub 1966: 64) was baited with a plastic egg. Birds were caught 2-20 min after setting the trap. One bird of each of five skua pairs (4 males, 1 female) were captured and one wing dyed. Sex was deduced from copulatory position. All activities of the currently nonincubating partner were recorded for periods of 2-5 h at a time. Observations on three pairs (blue, green, and white dyed) were spread throughout the incubation period. Nest positions are indicated in Fig. 1. Each pair was watched for $24 \mathrm{~h}$ and its territory mapped as accurately as possible. All points at which pair partners showed defense activities against other skuas were recorded, 100-200 such points being mapped for each of the 3 territories. A line connecting the outermost points at which such attacks occurred enclosed an area identical with the hunting area of the skua pair concerned. This is assumed to indicate the maximum territorial extension.

The other 2 dye-marked pairs were watched for $8 \mathrm{~h}$ and $18 \mathrm{~h}$ respectively. One pair separated towards the end of December, but the male still occupied the territory. Observations on the other pair were discontinued as the birds became disturbed.

The area called the "Hook" is shown in Fig. 1. Hunting flights were recorded in addition to territorial defense flights (= chases) to map the territories of skua pairs breeding on the Hook (Figs. 1 and 2). Only slightly more than $8 \mathrm{~h}$ were needed to map their territories as much of the information was already known from weekly controls, frequent census-taking at some penguin colonies, and other observations. On the average, six hunting flights and two chases were mapped for each territory on the Hook. For 2 territories, the mapped area increased $17 \%$ and $6 \%$ respectively from the second to the third 90 -min observation period on the same day. The actual territorial area should, therefore, be covered quite satisfactorily (for discussion of the method, see Odum and Kuenzler 1955). With this mapping method, errors in the determination of the maximum territorial extension may reach $20 \%$. The boundaries shown in Fig. 2 cannot, therefore, be regarded as absolutely exact.

\section{Penguin and Skua Populations at Hallett Station}

Hallett Station was built in 1956-57 on the edge of a penguin rookery on a flat peninsula covering 40.5 ha. According to Reid (1964) 62,900 penguin pairs were 


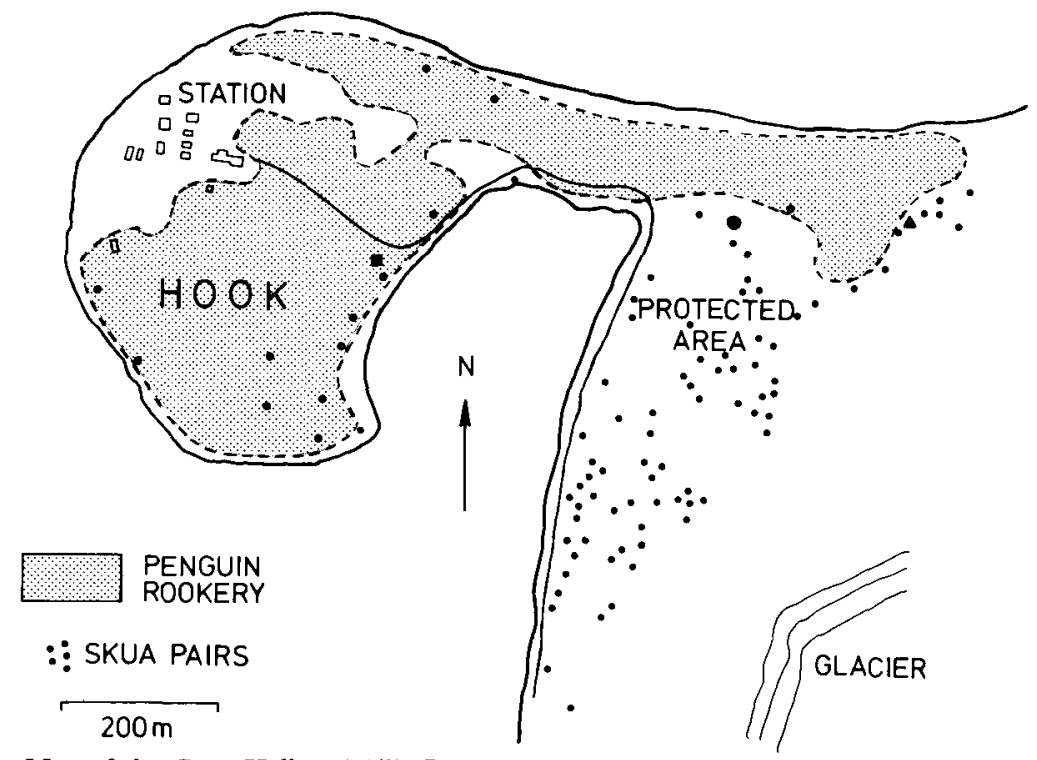

Fig. 1. Map of the Cape Hallett Adélie Penguin rookery with nest territories of 94 skua pairs (on 2 January 1972). The nests of the dye-marked pairs blue (square), green (circle), and white (triangle) are shown. The road from the station to the glacier cuts off the southwest part of the rookery referred to as the "Hook."

breeding at Hallett in 1959-60. The population declined until in 1967-68 it was estimated to be about 43,000 pairs (Tenaza 1971). Persecution by station personnel reduced the number of skua pairs from 181 in 1960-61 (Maher 1966) to 98 pairs in 1968-69 (Johnston 1971). In 1971-72 I also counted 98 skua pairs.

The area covered by the penguin rookery (after Reid 1964), the nest territories of skuas on 2 January 1972, and the terms used for different parts of the Hallett Station peninsula are given in Fig. 1. About $75 \%$ of the skua population in 1971-72 were active breeders, of which $10 \%$ bred in between penguin colonies, $20 \%$ on the edge of the rookery, and $70 \%$ farther away from the rookery in the protected area (a plant protection area).

Except when taking out trash, navy personnel never went into the penguin rookery during the 1971-72 season. In October navy personnel were feeding skuas near the galley. From about mid-November food was withheld, and all kitchen refuse was covered and burned weekly.

\section{Territory Establishment DURING November AND DeCEMbER}

The skuas arrived at Hallett in the last third of October. During the first half of November both partners of the pairs on the Hook began to attack skuas trespassing in their future nest territories. In search of food they ranged throughout most of the rookery, where in the first week of November their only food was carcasses of young penguins from the previous year. They were also seen feeding on garbage near the station galley and out on the sea ice, where they fed on the afterbirths of Weddell seals (Leptonychotes weddelli). More than $90 \%$ of their resting time was spent within their future territories.

From about mid-November (peak of penguin egg-laying 11 November 1971) the 


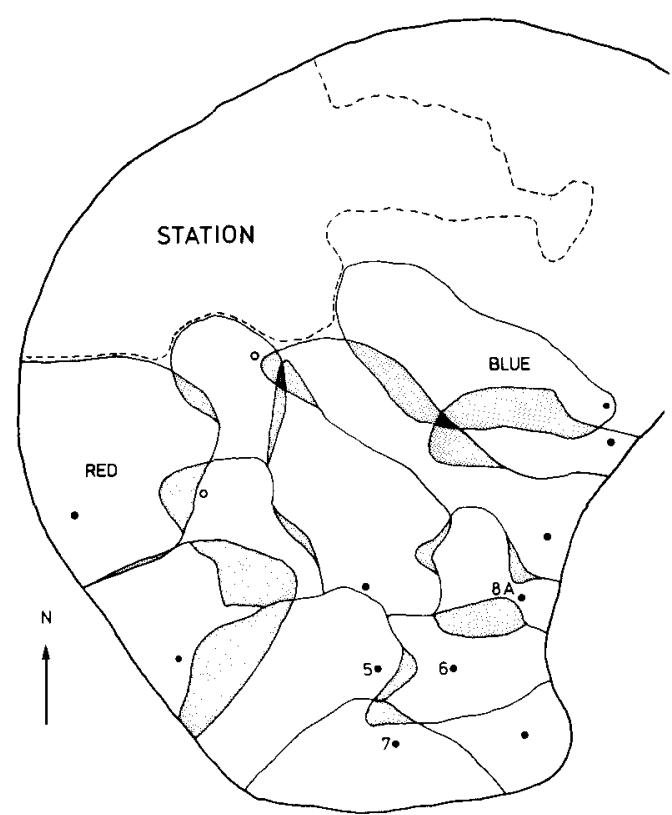

Fig. 2. Skua territories on the Hook with areas of overlap between adjacent territories stippled. The black dots indicate either the nest or roost of a pair. The upper circle shows the roost of a pair breeding in the protected area. The lower circle indicates the roost of a pair whose nest territory was not known.

dye-marked skuas (red, blue, green, and white) limited their hunting activities to their feeding territories, which they defended vigorously against skuas flying over or landing. After egg-laying (first skua clutch completed 20 November 1971) these skuas left their territories only for bathing (once or twice a day for 5-20 min), during brief chases, or for very rare foraging flights to the station galley.

\section{Territory Size AND Food Resources}

Twelve territories (that were nest and feeding territories simultaneously) were mapped on the Hook (one belonging to the pair dye-marked blue), three on the north edge of the protected area (one belonging to the pair dye-marked green) and one on the east edge of the rookery (of the pair dye-marked white). Territory sizes varied between 0.5 and 1.8 ha (median 1.1 ha). The number of penguin pairs in 13 of these territories was counted from an aerial photograph (U.S. Navy, 4 November 1970; this photo was kindly provided by Leigh $H$. Fredrickson). Numbers varied between 730 and 3,190 pairs. Territory size and the number of penguin pairs on a territory were significantly correlated (Spearman rank correlation: $r_{\mathrm{S}}=0.66 ; P<0.02$, twotailed test).

Territories overlapped deeply as shown in Fig. 2. The overlap with all adjacent territories amounted to $22 \pm 14 \%$ of the total territory area. Casual observations indicated that one of the pairs was dominant in such a region of overlap. For example, pair 6 seemed to be dominant over pair 7 but subordinate to pairs 5 and $8 \mathrm{~A}$ in the areas of overlap with their respective territories. Skuas other than neighbors from adjacent territories were chased out of the area of overlap by any of the territory owners concerned. 


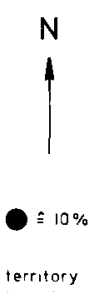

boundary

$---$

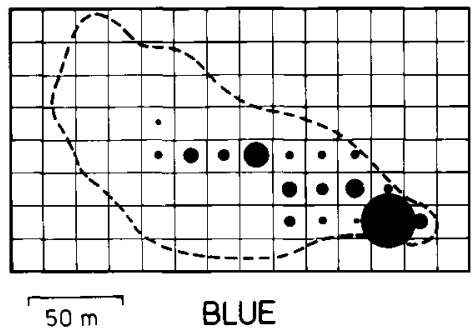

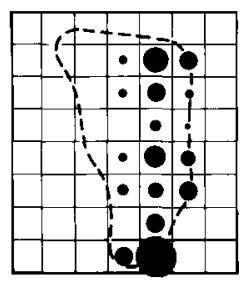

GREEN

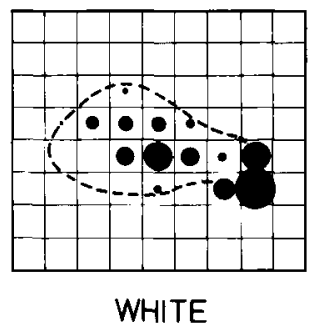

WHITE

Fig. 3. Utilization of the territory area on the ground by the three dye-marked pairs blue, green, and white, each observed for $24 \mathrm{~h}$. The largest dot, indicating longest occupation of the square by the nonincubating skua, always coincides with the position of the nest.

\section{Territory Utilization By The Dye-Marked Pairs}

To facilitate description, nest and feeding territories have been defined as if they were separate entities. But this was only rarely the case. The nest territory was located (1) among the penguin colonies, in which case it merged with the feeding territory, with the boundary difficult to define; (2) just outside the area colonized by penguins, with the penguin rookery boundary being considered to bound the nest territory also; (3) farther away from the rookery; most of these skua pairs had no feeding territories (see below).

The nest territory of the pair dye-marked blue belonged to the first type, the nest territories of the pairs dye-marked green and white to the second.

In these three pairs, the currently nonincubating bird stayed on the nest territory for about half its time off the nest. About $94 \%$ of the time on the nest territory the skuas rested on a little mound (roost), preening occasionally. The duration of a resting period averaged about $12 \mathrm{~min}(\mathrm{n}=151)$. As no penguins bred within $10-15 \mathrm{~m}$ around the nest, disturbance by trespassing penguins was very rare ( 4 in $32 \mathrm{~h}$ ). About four times per hour the nonincubating bird took off, usually to chase off strange skuas. During the skua incubation period about half the penguin chicks and eggs taken in the feeding territory were carried to the vicinity of the nest and consumed there.

The other half of their time off the nest these skuas spent on their feeding territories. Either directly after nest relief, or after some time on the roost, the skuas flew to the penguin colonies. On their feeding territories resting and preening combined took $72 \%$ of the skuas' time. These resting periods were shorter than those on the nest territory, averaging about $9 \mathrm{~min}(\mathrm{n}=133)$. The skuas often walked very close to the penguin colonies and were chased away by the penguins about three times per hour, sometimes for several meters.

For these three dye-marked pairs the total duration of stay at various sites in the territory was plotted from $24 \mathrm{~h}$ of observation. Resting and hunting activities on the ground were mostly confined to a few preferred sites in the territory. As is shown in Fig. 3 the "blue" pair used only $17(32 \%)$ out of 53 squares (one square $=$ ca. $300 \mathrm{~m}^{2}$ ) as landing and resting places, the "green" pair $17(66 \%)$ of 26 , and the "white" pair 14 $(66 \%)$ of 21 squares. Ground areas of heaviest utilization were the roost in the nest territory and usually one preferred resting site in the feeding territory. Although these birds usually hunted on the ground they defended a considerably larger area (maximal territory) when in the air, even considering the fact that of course they could not move within penguin colonies. The behavioral observations indicated that the feed- 


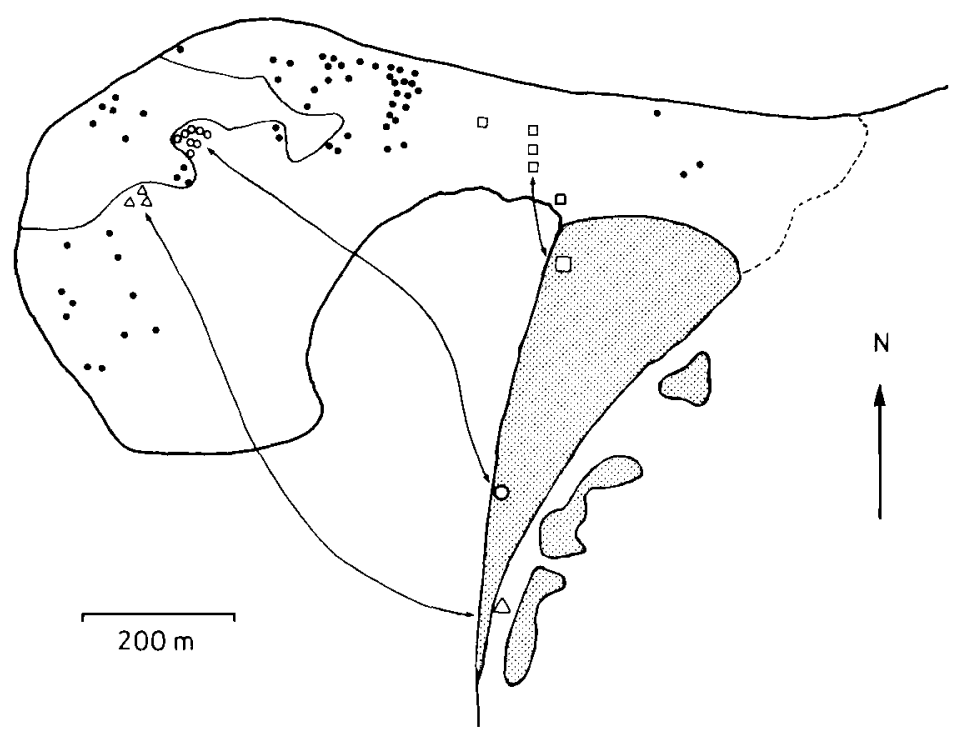

Fig. 4. Landing points of birds from the protected area in the penguin rookery (black dots). The shaded area indicates the region from which these birds took off. The other symbols show nest (larger symbol) and landing points (smaller symbol) of three pairs with separate nest and feeding territories.

ing territory with its penguin colonies was the only source of food for four of the dye-marked pairs during their incubation period.

In all these activities no significant differences between male and female were found. Qualitative observations show that a similar pattern was followed by the other skuas defending feeding territories.

\section{Subdivision of the Rookery Area between Skua Pairs WITH AND WITHOUT FEEDING TERRITORIES}

The dye-marked skuas, and all skua pairs on the Hook, claimed parts of the rookery as their feeding territories, as mapped in Fig. 2. Observations elsewhere in the rookery showed that its eastern parts were split up by the skuas breeding on its periphery into feeding territories adjacent to their nest territories. Three skua pairs (possibly four) breeding farther south in the protected area (see Fig. 4) also held feeding territories in the rookery. Whenever they were on their feeding territories they defended them successfully against other skuas.

More than $75 \%$ of the rookery space was occupied by about $30 \%$ of the skua population. Figure 5 shows that only the northwest part of the rookery was not occupied by territorial skua pairs.

\section{Foraging of Skuas without Feeding Territories}

All skuas of the protected area defended a space immediately surrounding their nests as nest territory. To feed they regularly flew to the penguin rookery.

During approximately $30 \mathrm{~h}$ of observations of the flight paths of skua pairs breeding in the protected area, birds were traced from takeoff near the nest to landing in the rookery 83 times. Their landing points were mapped and their behavior there was followed as long as the birds were clearly visible. Most often this was for only 


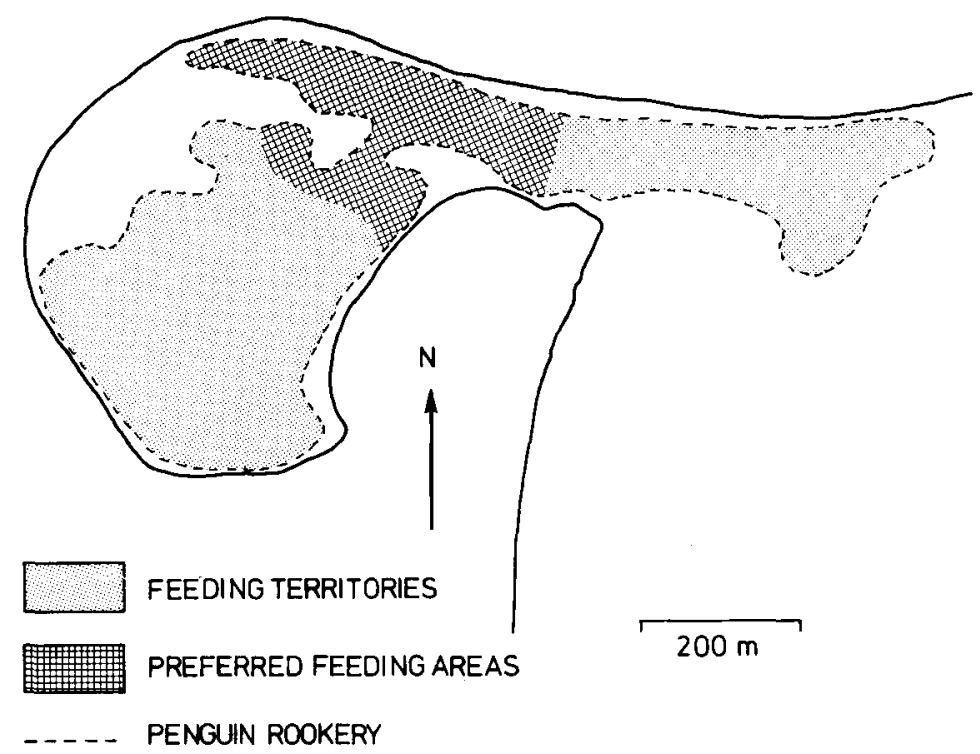

Fig. 5. Parts of the penguin rookery claimed as feeding territories or used as preferred feeding areas by skuas.

5-10 min, maximally for $45 \mathrm{~min}$. Some flights back to the nest in the protected area could also be mapped. The 83 traced flight paths included 16 flights of pairs holding feeding territories on the Hook (see Fig. 4). Of the 67 remaining flight paths 14 ended in places claimed as territory by other skuas, 9 in the station, and 36 in the northwest part of the rookery (Fig. 4), while on 8 occasions skuas taking off from the vicinity of the nest flew north or south, far beyond the rookery, presumably to feed at sea.

Skuas from the protected area alighting in parts of the rookery claimed as feeding territories by other skuas were usually driven off immediately. If they got any food at all they usually snatched it in a dive and carried their prey back to their nest territories. During the penguin egg-laying period, egg snatching from the feeding territories on the Hook by birds from the protected area was common. On their way back these skuas were often harassed by others and robbed of their prey. During the penguins' late guard and crêche stages a strange skua was never seen to kill a penguin chick on a feeding territory on the Hook, and only rarely succeeded in tearing a few scraps of flesh from the carcass of a young penguin.

Skuas landing in the northwest part of the rookery usually limited their hunting activities there to a region comparable in size to a feeding territory. For five skua

TABLE 1

Penguin Breeding Success in Relation to Exploitation by Skuas

\begin{tabular}{lcc}
\hline \hline & $\begin{array}{c}3 \text { penguin colonies } \\
\text { inside skua } \\
\text { feeding territories }\end{array}$ & $\begin{array}{c}3 \text { penguin colonies } \\
\text { inside skua } \\
\text { preferred feeding areas }\end{array}$ \\
\hline Maximum number of penguin pairs & 299 & 158 \\
Maximum number of active pairs & 249 & 124 \\
Maximum number of eggs & 460 & 219 \\
Maximum number of chicks & 389 & 183 \\
Hatching success & $84.6 \%$ & $83.6 \%$ \\
Breeding success to late guard stage & $79.4 \%$ & $80.4 \%$ \\
\hline
\end{tabular}


TABLE 2

SkUa Breeding Success in Relation to Feeding TerRitory 1971-72

\begin{tabular}{|c|c|c|c|c|c|c|}
\hline & $\begin{array}{l}\text { Total } \\
\text { pairs }\end{array}$ & $\begin{array}{l}\% \text { of pairs } \\
\text { with } E \\
\text { or } C\end{array}$ & $\begin{array}{l}\text { Total } \\
\text { eggs }^{1}\end{array}$ & $\begin{array}{c}\text { Total } \\
\text { chicks }^{1}\end{array}$ & $\begin{array}{c}\mathrm{E} \text { and } \mathrm{C} \\
\text { per total } \\
\text { pairs }\end{array}$ & $P^{2}$ \\
\hline \multicolumn{7}{|c|}{ 9-11 December 1971} \\
\hline $\begin{array}{l}\text { prs with f.t. }{ }^{3} \\
\text { prs w/o f.t. }\end{array}$ & $\begin{array}{l}26 \\
72\end{array}$ & $\begin{array}{l}88 \\
63\end{array}$ & $\begin{array}{l}42 \\
67\end{array}$ & $\begin{array}{l}0 \\
0\end{array}$ & $\begin{array}{l}1.6 \\
0.9\end{array}$ & $<0.001$ \\
\hline \multicolumn{7}{|l|}{2 January 1972} \\
\hline $\begin{array}{l}\text { prs with f.t. } \\
\text { prs w/o f.t. }\end{array}$ & $\begin{array}{l}28 \\
72\end{array}$ & $\begin{array}{l}82 \\
71\end{array}$ & $\begin{array}{r}9 \\
43\end{array}$ & $\begin{array}{l}25 \\
29\end{array}$ & $\begin{array}{l}1.2 \\
1.0\end{array}$ & $<0.5$ \\
\hline \multicolumn{7}{|c|}{ 20-22 January 1972} \\
\hline $\begin{array}{l}\text { prs with f.t. } \\
\text { prs w/o f.t. }\end{array}$ & $\begin{array}{l}28 \\
72\end{array}$ & $\begin{array}{l}75 \\
65\end{array}$ & $\begin{array}{l}2 \\
4\end{array}$ & $\begin{array}{l}28 \\
49\end{array}$ & $\begin{array}{l}1.1 \\
0.7\end{array}$ & $<0.02$ \\
\hline
\end{tabular}

pairs the flight paths of male and female were followed several times. Partners usually landed independently of each other in the same region in the northwest part of the rookery. Skuas in the near neighborhood did not react visibly to displays given by alighting birds. These usually remained for some time near their first landing point, hunting on the ground and on the wing, until their flight back to the nest territory. These observations suggest that both partners of a skua pair used the same limited part of the rookery as preferred feeding area.

\section{Penguin Breeding Success on Skua Feeding Territories and on Skua Preferred Feeding Areas}

The ecological density of skua pairs with feeding territories was about 1.8 pairs/ha rookery area, that of pairs with preferred feeding areas in the northwest part of the rookery 12 pairs/ha rookery area. The latter value may be a little too high as some of these pairs searched for food at sea. To establish whether skua density affected penguin breeding success, six colonies on the Hook inside skua feeding territories and six in the northwest part of the rookery used as preferred feeding areas were checked at regular intervals. The colonies were entered and nest checks made from egg-laying through late guard stage (4 November-28 December 1971) (Table 1). No significant difference in the breeding success of penguins breeding inside skua feeding territories or on skua preferred feeding areas was found.

\section{Breeding Success of Skua Pairs with and without FEEDING TERRITORIES}

An advantage or disadvantage afforded by feeding territories or the use of preferred feeding areas and/or foraging at sea could be indicated by differences in breeding success. To establish any possible differences three censuses of the skua population were made in 1971-72.

All pairs holding nest territories were mapped. For the calculation of breeding success of the two groups of birds (with or without feeding territories), in either group the maximum number of pairs holding nest territories was used. In the first two censuses the skuas were not removed from the nest, and it was noted only whether 
they were incubating or had chicks, which was evident from their behavior. About $90 \%$ of the birds took off when the observer approached, whereupon nest contents were checked. In the last census (20-22 January 1972) the contents of all nests were checked.

Pairs with feeding territories began to breed about 8-10 days earlier than the other pairs. At the first census of 9-11 December 1971 most of the pairs with feeding territories already had eggs, while many of the other pairs were still in courtship. Also, in the census of 2 January 1972, pairs with feeding territories had significantly higher ratios of chicks to eggs than pairs without ( $\chi^{2}$ test; $P<0.001$ ).

In all three censuses pairs with feeding territories averaged more eggs and/or chicks per pair than pairs without feeding territories. In the first census (Table 2) I did not know the contents of a few nests. Even when all unknown nests of birds without feeding territories $(n=8)$ are assumed to contain 2 eggs and all unknown nests of birds with feeding territories $(n=3)$ to contain $1 \mathrm{egg}$, the difference in eggs/pair between the two groups is still significant $\left(\chi^{2}\right.$ test; $\left.P<0.02\right)$, but this only indicates that the pairs with feeding territories began to breed earlier than those without. In the second census (Table 2) at the end of the incubation period both groups averaged the same brood size, so that up to this time the only difference between the two groups lay in the onset of breeding. After hatching chick mortality was much lower in pairs with feeding territories than in pairs without, which is expressed in the significantly higher breeding success of the former group (Table 2).

\section{Discussion}

The penguin-skua system described in this paper has been greatly disturbed by the establishment of the station and the activities there (Fredrickson 1971). The skua population declined to ca. $54 \%$ and the penguin population to ca. $67 \%$ of ti.eir former sizes. Spatial arrangements and the relation of skuas to penguins may have changed considerably, and the relatively great food resources available to some skua pairs at Hallett may have been created artificially. Bekoff (pers. comm.) reported spacerelated behavior of skuas at Cape Crozier similar to that at Hallett, and D. and C. Müller-Schwarze (1973) gave a description of the skuas' foraging behavior at Cape Crozier, which also applies to the skuas at Hallett. Thus the situation at Hallett may not be so artificial as the dramatic population decrease of penguins and skuas suggests. The comparison of the skuas' widely differing foraging and territorial behavior in the same rookery and of its consequences for the skuas can be conducted regardless of how close the penguin-skua system is to its former natural state.

Foraging.-Until the end of January, the pairs dye-marked blue, green, and white supported themselves exclusively from their rookery feeding territories. Food should have been plentiful for these skua pairs even after the penguins had left Hallett, because every spring many intact carcasses of penguin chicks from the preceding season remain, frozen through the winter. This means that although the skuas' breeding cycle is not adapted to that of the Adélie Penguin (Spellerberg 1975), territorial behavior should enable some skua pairs at Hallett to subsist exclusively on the penguin food resources until the very end of the skua breeding season. This they more likely achieve by safeguarding food resources on their feeding territories from other skuas, than by actively preying on the penguins. D. and C. Müller-Schwarze (1973) described a strategy of this kind for skuas at Cape Crozier.

Young's opinion (1963b) that the skua is more a scavenger than a predator in 
Adélie Penguin rookeries is borne out by the finding that no disparity exists in penguin breeding success on skua feeding territories or on skua preferred feeding areas with their sixfold higher skua density. This contrasts markedly with Nettleship's (1972) data on the predator-prey interactions between gulls (Larus marinus and L. argentatus) and the Common Puffin (Fratercula arctica). He reports that the fledging success of $90.5 \%$ of puffins in colonies without gulls fell to $37.1 \%$ in colonies with gull interference.

Breeding success.- On the average, skuas with feeding territories in the rookery had greater breeding success than pairs without. Several factors singly or in combination, could account for this finding:

(1) Young (1963a) gave examples of pugnacious fighting between skua chicks within the first week of the second chick hatching, and often proving fatal for the second chick. At hatching time of the skua chicks a feeding territory in the penguin rookery at Hallett provided a skua pair with an abundant, easily accessible food supply. In very short hunits these skuas could secure more than their own and their chicks' needs, as evidenced by food cached near the nest. This allowed each parent skua to care for one chick nearly continuously, thus keeping them separated and avoiding combat. In pairs without feeding territories, whether they fed on preferred feeding areas or at sea, one parent was often away for hours, and it could have been difficult for the other parent to prevent chick fighting (example see Young 1963a: 222).

Therefore the abundant food supply from a rookery feeding territory (also available in unfavorable weather) together with the much longer periods of attendance of both parents at the nest site are considered to increase the survival chances of the second chick greatly. This would enhance the breeding success of the skua pairs with feeding territories over that of the pairs with preferred feeding areas.

(2) It is known in the South Polar Skua (Wood 1971) as well as in the Arctic Skua (Stercorarius parasiticus) that pairs breeding early have a higher reproductive success than later ones. In the Arctic Skua the males of the early pairs are usually darker in color (O'Donald et al. 1974). O'Donald et al. (1974) explained these results by assuming that the fittest females begin to breed earliest. Because of their higher fitness they produce on the average more young than other females. These authors suggested that these fittest females, when first breeding, choose the darker males.

No conspicuous differences in the relative frequency of dark and light phase males with and without feeding territories were evident at Hallett. For these skuas it therefore seems equally plausible to assume that the fittest females, when first breeding, select males because they have obtained the better territories in the rookery in male-male competition (see Mayr 1972: 95). This could account for the observed earlier onset of breeding in skua pairs with feeding territories. The above average fitness of these females (if O'Donald's assumptions are correct) may also play a part in the greater breeding success of such pairs.

(3) Skua nest density is positively correlated with intraspecific predation on eggs and chicks (Burton 1968). Therefore intraspecific predation should have affected pairs with feeding territories, where nest density is lower (see Fig. 1) less than pairs with preferred feeding areas. Also adult birds of pairs with feeding territories did not have long journeys from the nest to forage, so that their eggs and chicks may have been better protected against predation by conspecifics. At Hallett predation of skuas on skua eggs was observed only once in 1971-72 and may scarcely have impaired breeding success of pairs with preferred feeding areas. 


\section{ACKNOWLEDGMENTS}

This study was supported by the Deutsche Forschungsgemeinschaft grant $\operatorname{Tr} 105 / 1$ and by the National Science Foundation grant GA-23744 to John R. Baker, Iowa State University. He has earned my gratitude by generously making it possible for me to work at Hallett, and for his advice on the manuscript. I thank Rainer Hertel for his whole-hearted support before and after this study. Dirk V. Derksen, Chuck Steffen, and Jerry Weinrich kindly assisted in the field and with many stimulating discussions. Constructive criticism by M. Casimir, E. Curio, L. H. Fredrickson, H. Hoek, D. Müller-Schwarze, C. and P. Rechten, B. Svoboda, and M. W. Weller greatly improved the manuscript. It is a pleasure to recall the support given me by the U.S. Navy Support Force and especially the 1971-72 crew at Hallett Station. P. and C. Rechten kindly helped translate the manuscript.

\section{Literature Cited}

BuB, H. 1966. Vogelfang und Vogelberingung, I. Wittenberg, A. Ziemsen Verlag.

Burton, R. W. 1968. Breeding biology of the Brown Skua, Catharacta skua lönnbergi (Mathews), at Signy Island, South Orkney Islands. Brit. Antarct. Surv. Bull. 15: 9-28.

Fredrickson, L. H. 1971. Environmental awareness at Hallett Station. Antarctic Journal, U.S. 6: 57. Johnston, B. R. 1971. Skua numbers and conservation problems at Cape Hallett, Antarctica. Nature 231: 468.

Maher, W. J. 1966. Predations impact on penguins. Nat. Hist. 75: 42-51.

MAyr, E. 1972. Sexual selection and natural selection. Pp. 87-104 in Sexual selection and the descent of man 1871-1971 (B. Campbell, Ed.). London, Heinemann.

Müller-SChwarze, D., AND C. Müller-SchWARZE. 1973. Differential predation by South Polar Skuas in an Adélie Penguin rookery. Condor 75: 127-131.

Nettleship, D. N. 1972. Breeding success of the Common Puffin (Fratercula arctica L.) on different habitats at Great Island, Newfoundland. Ecol. Monogr. 42: 239-268.

Noble, G. K. 1939. The role of dominance in the life of birds. Auk 56: 263-273.

O'DOnAld, P., N. S. Wedd, ANd J. W. F. Davis. 1974. Mating preferences and sexual selection in the Arctic Skua. Heredity 33: 1-16.

Odum, E. P., And E. J. Kuenzler. 1955. Measurement of territory and home range size in birds. Auk 72: $128-137$.

Penney, R. L. 1968. Territorial and social behavior in the Adélie Penguin. Pp. 83-131 in Antarctic bird studies (O. L. Austin, Jr., Ed.). Washington, D.C., Amer. Geophs. Union.

Perdeck, A. C. 1960. Observations on the reproductive behavior of the Great Skua or Bonxie, Stercorarius skua skua (Brünn), in Shetland, Ardea 48: 111-136.

Reid, B. E. 1964. The Cape Hallett Adélie Penguin rookery-its size, composition and structure. Rec. Dom. Mus. Wellington 5: 1-37.

Spellerberg, I. F. 1975. The predators of Penguins. Pp. 413-434 in The Biology of Penguins (B. Stonehouse, Ed.). London and Basingstoke, MacMillan Press.

Tenaza, R. 1971. Behavior and nesting success relative to nest location in Adélie Penguins (Pygoscelis adeliae). Condor 73: 81-92.

WooD, R. C. 1971. Population dynamics of breeding South Polar Skuas of unknown age. Auk 88: 805-814.

Young, E. C. 1963a. The breeding behavior of the South Polar Skua, Catharacta maccormicki. Ibis 105: 203-233.

- 1963b. Feeding habits of the South Polar Skua, Catharacta maccormicki. Ibis 105: 301-318. 